\title{
Spatial synchrony in the recruitment of intertidal invertebrates along the coast of central Chile
}

\author{
Nelson A. Lagos $^{1,2}{ }^{\text {, Fabián J. Tapia }}{ }^{1}$, Sergio A. Navarrete ${ }^{1, *}$, Juan Carlos Castilla ${ }^{1}$ \\ ${ }^{1}$ Estación Costera de Investigaciones Marinas \& Center for Advanced Studies in Ecology and Biodiversity (CASEB), \\ Pontificia Universidad Católica de Chile, Casilla 114-D, Santiago, Chile \\ ${ }^{2}$ Present address: Departamento de Ciencias Básicas, Universidad Santo Tomás, Ejército 146, Santiago, Chile
}

\begin{abstract}
Recruitment is among the processes that most directly influence spatio-temporal patterns of abundance, productivity, and persistence in marine populations. Understanding the connection between patterns of recruitment and environmental forcing has major implications for the conservation and management of marine ecosystems. Theoretical and empirical studies have shown that dispersal and regional variability in environmental conditions may synchronize distant populations and generate patterns of spatial synchrony (i.e. decay in synchrony with distance). Here, we submit that recruitment synchrony patterns may be used to identify processes shaping the distribution of marine populations. We used artificial substrates to estimate patterns of spatial synchrony in recruitment for 15 intertidal invertebrates at 16 exposed rocky platforms spanning $120 \mathrm{~km}$ of the central coast of Chile. Clear and significant synchrony patterns were found for only 4 species: the barnacles Jehlius cirratus, Notochthamalus scabrosus, and Notobalanus flosculus, and the bivalve Perumytilus purpuratus, all of which occur at comparatively high abundance across the study region. The strength of synchrony decayed with distance, from positively correlated fluctuations for sites separated by $<30 \mathrm{~km}$, to negatively correlated for sites $>40 \mathrm{~km}$ apart. Patterns of spatial synchrony in recruitment resembled those of fluctuations in sea surface temperature, suggesting that mesoscale processes such as coastal upwelling may shape recruitment patterns by way of modulating larval dispersal. A lack of clear synchrony patterns in the remaining species could be ascribed to their low abundance, or, for those with potentially limited larval dispersal (e.g. direct development), it could indicate our lack of adequate spatio-temporal resolution to detect recruitment variability at small scales.
\end{abstract}

KEY WORDS: Spatial synchrony · Benthic invertebrates · Recruitment - Upwelling · Dispersal Resale or republication not permitted without written consent of the publisher

\section{INTRODUCTION}

Recruitment is among the processes that most directly influence spatio-temporal patterns of abundance and geographic distributions in marine populations (Thorson 1950). Within coastal regions, recruitment of benthic invertebrates with a planktonic larval stage is modulated by local and mesoscale physical processes affecting larval dispersal (Roughgarden et al. 1988), and by environmental forces acting on both adults and larvae at a regional scale (Connolly \& Roughgarden 1999, Navarrete et al. 2002). Interactions between spatially structured environmental processes driving larval dispersal and local factors affecting postsettlement survival (e.g. substrate type, exposure, predation, competition) may give rise to spatial patterns in recruitment (Lagos et al. 2005). For instance, changes in the intensity of coastal upwelling may greatly influence larval dispersal and, by extension, determine spatio-temporal patterns in settlement, recruitment, and geographic distributions of species with complex life cycles (Roughgarden et al. 1988, Botsford 2001). In fact, a number of recent studies have shown that spatial variability in upwelling intensity may induce corresponding meso- to regional-scale spatial patterns in the recruitment of benthic invertebrates with plank- 
tonic larvae (e.g. Connolly \& Roughgarden 1998, Connolly et al. 2001, Navarrete et al. 2002, 2005, Lagos et al. 2005).

The role of dispersal versus environmental forcing as drivers of spatio-temporal variability in population abundance is a pervasive theme in ecology. Spatial synchrony, i.e. the correlation of temporal fluctuations in abundance among distant populations, has been extensively studied and reviewed within the context of terrestrial populations (Liebhold et al. 2004). Spatial synchrony can be induced by density-independent environmental factors that couple distant populations controlled by a common density-dependent structure - also known as the 'Moran effect' (Ranta et al. 1997) - and by the dispersal of individuals into nearby areas (Bjørnstad \& Bolker 2000). Theoretical and empirical studies have shown that synchrony declines with geographic distance between sites, and that the shape of this decay depends on which factor (i.e. dispersal or spatially correlated environmental variability) is more important in synchronizing distant populations (Ranta et al. 1997, Bjørnstad et al. 1999). For example, increasing dispersal distances increases synchrony among nearby populations and accentuates the pattern of decreasing correlation at larger spatial scales (Ranta et al. 1997, Labra et al. 2003). In the case of organisms with limited dispersal, the synchronizing effect of dispersal can be small relative to environmentally-induced spatial synchrony in population abundances (Hanski \& Woiwod 1993). Thus, deconstructing observed patterns of spatial synchrony may prove helpful in assessing the relative influence of each of these factors on local and regional population dynamics (Bjørnstad et al. 1999).

In the marine environment, and particularly in the case of benthic species with sessile adults and planktonic larvae, spatial patterns in the synchrony of adult abundance fluctuations have been ascribed to spatially correlated processes affecting recruitment (Burrows et al. 2002). A spatial pattern of recruitment synchrony implies that processes determining spatial and temporal variation in larval arrival to adult habitats and/or post-settlement survival operate simultaneously and over a finite spatial domain along the coast. Thus, the existence of synchronous fluctuations in recruitment over a given distance could provide clues as to the process or processes that underlie them (Pineda 2000), provided that information on the dispersal potential of larvae is also available. Marine organisms exhibit an astonishing diversity of dispersal potentials (Thorson 1950, Eckert 2003, Shanks et al. 2003, Siegel et al. 2003), which are largely determined by differences in the mode and duration of larval development (Strathmann 1987, Levin \& Bridges 1995). For instance, scales of dispersal in species with planktonic larvae that com- plete development within days to weeks are strongly influenced by mesoscale transport mechanisms such as coastal upwelling (Roughgarden et al. 1988, Ebert et al. 1994). On the other hand, chances for mesoscale oceanographic processes to influence spatio-temporal patterns of recruitment are much reduced in species that have short larval durations or lack a free-swimming larval stage (i.e. direct development).

Differences in abundance and numbers notwithstanding, species with all of these types of larval development may be found coexisting along a stretch of coastline, interacting in different ways with dominant environmental processes (Kinlan \& Gaines 2003, Shanks et al. 2003). In this study, we estimated patterns of synchrony in the recruitment of dominant and coexisting intertidal benthic invertebrates along $120 \mathrm{~km}$ of exposed rocky coast of central Chile. Degree and spatial scales of synchrony were compared among recruitment time series gathered at $15 \mathrm{~d}$ intervals for intertidal species with differing modes of larval development (barnacles, bivalves, gastropods, and sea urchins). We hypothesized that species with planktonic larvae are more likely to show region-wide synchronous fluctuations in recruitment, whereas species with direct development should exhibit uncorrelated recruitment dynamics among sites. We found that recruitment synchrony does indeed occur in species with planktonic larvae, but it was detectable in only 4 species (barnacles and mussels), all of which recruit at high rates within the study region. Species with similar larval development but less intense recruitment, as well as species with direct development, showed spatially heterogeneous recruitment dynamics. Coastal processes affecting mesoscale patterns in sea surface temperature (e.g. upwelling dynamics) seemed to modulate the scale of recruitment synchrony in barnacles and mussels. We discuss the implications of the scales of synchrony for conservation and management, as well as the potential link between an apparent lack of recruitment synchrony in species with short larval durations or direct development and the spatio-temporal resolution of our observations.

\section{MATERIALS AND METHODS}

The study was conducted at 16 sites along $120 \mathrm{~km}$ of the coast of central Chile (Fig. 1). Details of the study sites were presented by Lagos et al. (2005), where spatial patterns in recruitment of intertidal barnacles are presented. Briefly, at each site we monitored barnacle recruitment using $10 \times 10 \mathrm{~cm}$ plexiglass plates covered with a rubbery standard surface (Safety-walk, 3M; Menge 2000). Four plates were deployed at each site in 


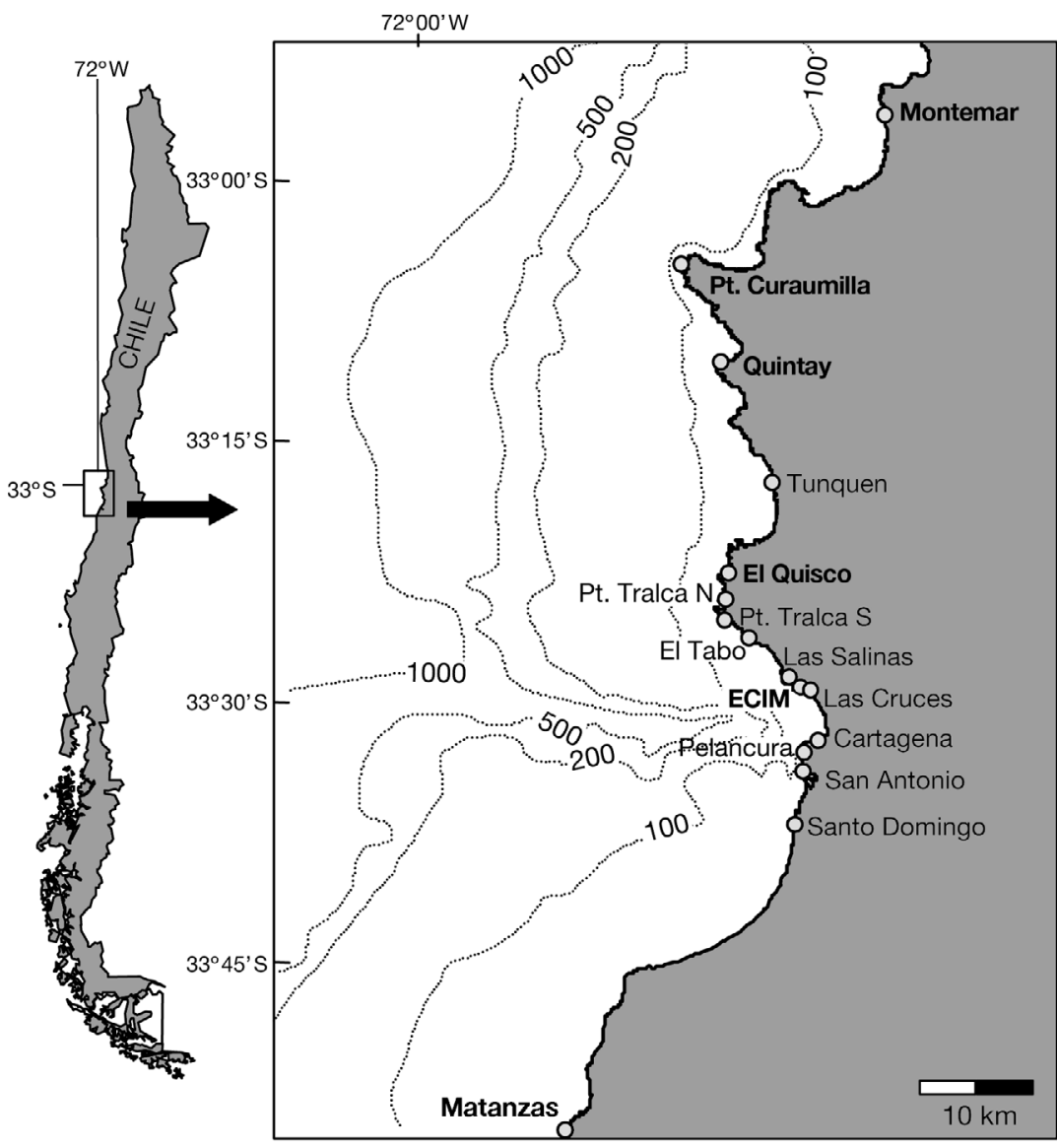

Fig. 1. Central Chilean coastline (black solid line) with geographic locations of the 16 study sites (gray circles). Dotted lines correspond to isobaths (m). Site labels in bold indicate locations for which $4 \mathrm{yr}$ series of seasonal SST variability were available (see 'Materials and methods' and Fig. 5D)

and early summer is dominated by wind-induced upwelling, which generates mesoscale variability in SST (Narváez et al. 2004, 2006). We measured in situ SST with StowAway TidbiT loggers (Onset Computer Corporation) deployed in shallow subtidal waters (ca. $1 \mathrm{~m}$ deep) at each site, which recorded point measurements every $30 \mathrm{~min}$. Previous observations for this region have shown consistent patterns of alongshore variability when in situ SST data are compared to coastal temperatures from high-resolution satellite imagery (Lagos et al. 2005). Furthermore, low in situ temperatures strongly correlate with high nitrate concentrations in the shallow subtidal zone (Wieters 2005). Thus, onshore temperature appears to be a good proxy for the main oceanographic processes driving SST variability in the region.

The spatial structure of SST fluctuations was investigated using (1) the raw dataset, which included temperature fluctuations from 30 min to nearseasonal scales observed during the 7 mo long study period, (2) a time series with synoptic-scale variability (i.e. periods of 2 to $10 \mathrm{~d}$ ), obtained by processing the original temperature series with a band-pass filter that only left temporal fluctuations in SST

the mid (approximately 60 to $80 \mathrm{~cm}$ above mean lower low water, MLLW) and low (20 to $40 \mathrm{~cm}$ above MLLW) intertidal zones. Observations on bivalve and gastropod recruitment were gathered using a globular mesh of plastic filaments or Tuffy ${ }^{\circledR}$ pads (Martínez \& Navarrete 2002). Four Tuffy pads per site were deployed in the mid-intertidal level. Plates and Tuffy pads were spread along 10 to $30 \mathrm{~m}$ long transects parallel to the coastline of rocky platforms, exposed to similar wave action. Between August 2002 and February 2003, and depending on weather conditions, plates and Tuffys were replaced at biweekly intervals (within $15.2 \pm$ $0.3 \mathrm{~d})$ and brought to the laboratory for identification under a dissecting microscope. This sampling scheme yielded 16 recruitment time series (i.e. 1 per site) for barnacles, bivalves, gastropods, and sea urchins.

We used time series sea surface temperature (SST), measured in situ from August 2002 to February 2003, as a proxy for the intensity of coastal upwelling and other meso-scale ( 1 to tens of $\mathrm{km}$ ) processes. In this region, nearshore oceanography during austral spring occurring at frequencies of 0.5 to 0.1 cycles per day (cpd), and (3) variability at semi-hourly to daily scales (hereafter 'hourly' scales), for which the raw data were filtered using a 145 weighted Lanczos cosine filter that removed frequencies lower than $0.5 \mathrm{cpd}$ (i.e. periods $>2 \mathrm{~d}$ ). Additionally, to better represent variation in the seasonal cycle across the region and over longer time periods, (4) series of monthly means for SST recorded at 6 of the 16 sites (see Fig. 1) over a 4 yr period were used to assess whether among-site correlation in the seasonal cycle changed as a function of distance.

Data analyses. We assessed spatial synchrony in recruitment by calculating the overall relationship between geographic distance and among-site correlations of recruitment series for each species. Two matrices were calculated for each species: a 'distance matrix' with Euclidean distances between all pairs of sites, and a 'correlation matrix' consisting of all possible pairwise Kendall $\tau$-b correlations between recruitment time series (Buonaccorsi et al. 2001). To test for the significance of a spatial decay in synchrony with 
geographic distance (hereafter 'spatial synchrony pattern') we used a Mantel test (Mantel 1967) that included the entire distance and correlation matrices. To further explore the nature of the synchrony pattern for those species that exhibited a significant pattern, and since the Mantel test does not provide an indication of the spatial scales involved, we computed standardized Mantel correlograms for 9 distance bins (Fortin et al. 2003). The standardized Mantel statistic is positive when the correlation within a given bin is higher than the average across bins (i.e. background or regional correlation), and it is negative when the correlation is lower. Thus, when among-site correlation declines with distance, the point at which the correlogram becomes negative provides an estimate of the spatial scale of synchrony in recruitment. Significance of the standardized Mantel statistic $\mathrm{r}$ was calculated using 1000 permutations and corrected for multiple comparisons with a sequential Bonferroni approximation (Legendre \& Legendre 1998). To distinguish temporal correlations that are due to low-frequency trends in recruitment (i.e. months to several months) from those due to biweekly fluctuations (i.e. among sampling dates), we decomposed each raw time series into (1) a trend, described by a third-order polynomial fitted to each local recruitment time series, and (2) shortterm fluctuations in recruitment $(R C)$ calculated as the difference in the abundance of recruits between consecutive sampling dates $\left(R c_{\mathrm{t}}-R C_{\mathrm{t}-1}\right)$. These analyses were performed only for October to December 2002 in the case of barnacles, because, outside that period, recruitment of the 3 species considered here was almost 0 (see our Results and Lagos et al. 2005). For other taxa, recruitment took place over the entire study

Table 1. Recruitment on artificial substrata at 16 sites spanning ca. $120 \mathrm{~km}$ of the central Chilean coastline. Mean settlement rates $( \pm 1 \mathrm{SD})$ of gastropods, bivalves, and echinoids were computed from 4 collectors (Tuffy pads), whereas mean recruitment rate of barnacles were computed from 8 plates per site. Number of sites and sampling times where each taxon occurred are indicated together with larval mode of development (D: direct development, P: planktotrophic larvae, L: lecithotrophic larvae). Spatial synchrony in recruitment was assessed with a Mantel coefficient of correlation ( $\mathrm{r}_{\text {Mantel }}$ ) for taxa with $\mathrm{n} \geq 16$ (i.e. total number of sites), and at least 7 sites were found. Bold: significant spatial synchrony. Significance was evaluated through 1000 permutations of the distance matrix

\begin{tabular}{|c|c|c|c|c|c|c|}
\hline Taxon & $\begin{array}{l}\text { Recruitment rate } \\
\text { (ind. collector }{ }^{-1} \mathrm{~d}^{-1} \text { ) }\end{array}$ & $\mathrm{n}$ & $\begin{array}{l}\text { No. } \\
\text { sites }\end{array}$ & $\begin{array}{l}\text { No. } \\
\text { times }\end{array}$ & $\begin{array}{l}\text { Larval } \\
\text { mode }\end{array}$ & $\begin{array}{l}\text { Synchrony } \\
\mathrm{r}_{\text {Mantel }}\end{array}$ \\
\hline \multicolumn{7}{|l|}{ CIRRIPEDIA } \\
\hline Jehlius cirratus & $5.548 \pm 20.26$ & 49229 & 16 & 11 & $\mathrm{P}$ & -0.695 \\
\hline Notochthamalus scabrosus & $4.010 \pm 12.69$ & 32007 & 16 & 8 & $\mathrm{P}$ & -0.496 \\
\hline Notobalanus flosculus & $4.634 \pm 18.05$ & 43124 & 16 & 12 & $\mathrm{P}$ & -0.412 \\
\hline \multicolumn{7}{|l|}{ BIVALVIA } \\
\hline Lasaea sp. & $0.002 \pm 0.016$ & 22 & 9 & 8 & $\mathrm{D}$ & -0.171 \\
\hline Perumytilus purpuratus & $0.500 \pm 1.863$ & 5216 & 16 & 11 & $\mathrm{P}$ & -0.265 \\
\hline Semimytilus algosus & $0.197 \pm 0.545$ & 1973 & 16 & 11 & $\mathrm{P}$ & -0.030 \\
\hline Brachidontes granulata & $0.010 \pm 0.036$ & 100 & 11 & 11 & $\mathrm{P}$ & -0.128 \\
\hline Aulacomya ater & - & 1 & 1 & 1 & $\mathrm{P}$ & - \\
\hline Choromytilus chorus & $0.003 \pm 0.022$ & 30 & 3 & 5 & $\mathrm{P}$ & - \\
\hline \multicolumn{7}{|l|}{ GASTROPODA } \\
\hline Austrolittorina araucana & $0.133 \pm 0.323$ & 1382 & 16 & 11 & $\mathrm{~L}$ & -0.134 \\
\hline Siphonaria lessoni & $0.020 \pm 0.111$ & 201 & 16 & 11 & $\mathrm{~L}$ & 0.017 \\
\hline Mitrella unifasciata & $0.002 \pm 0.011$ & 16 & 7 & 8 & $\mathrm{~L}$ & -0.170 \\
\hline Sinezona rimuloides & & 1 & 1 & 1 & $\mathrm{~L}$ & - \\
\hline Turritella cingulata & & 1 & 1 & 1 & $\mathrm{P}$ & - \\
\hline Eatoniella glomerosa & $0.007 \pm 0.027$ & 66 & 8 & 11 & $\mathrm{D}$ & -0.019 \\
\hline Eatoniella nigra & $0.0004 \pm 0.006$ & 4 & 1 & 4 & $\mathrm{D}$ & - \\
\hline Acanthina monodon & & 1 & 1 & 1 & $\mathrm{D}$ & - \\
\hline Crepidula spp. & & 1 & 1 & 1 & $\mathrm{D}$ & - \\
\hline Tricolia umbilicata & $0.007 \pm 0.034$ & 64 & 13 & 11 & $\mathrm{P}$ & 0.103 \\
\hline Prisogaster niger & $0.003 \pm 0.016$ & 26 & 11 & 8 & $\mathrm{~L}$ & 0.041 \\
\hline Fissurella spp. & $0.001 \pm 0.008$ & 9 & 5 & 6 & $\mathrm{~L}$ & - \\
\hline Tegula spp. & $0.001 \pm 0.007$ & 6 & 4 & 5 & $\mathrm{~L}$ & - \\
\hline Tegula atra & $0.001 \pm 0.010$ & 7 & 3 & 4 & $\mathrm{~L}$ & - \\
\hline Scurria spp. & $0.006 \pm 0.028$ & 122 & 16 & 10 & $\mathrm{~L}$ & -0.062 \\
\hline Concholepas concholepas & $0.001 \pm 0.007$ & 6 & 5 & 4 & $\mathrm{P}$ & - \\
\hline \multicolumn{7}{|l|}{ ECHINOIDEA } \\
\hline Sea urchins & $0.025 \pm 0.130$ & 251 & 14 & 16 & $\mathrm{P}$ & -0.034 \\
\hline
\end{tabular}


period; hence synchrony was investigated using the complete data set. Finally, analyses of spatial synchrony similar to those described for recruitment data were performed on all SST time series.

\section{RESULTS}

We recorded recruitment rates for 26 benthic species: 5 direct developers, 9 with lecitotrophic larvae, and 12 with planktotrophic larvae (Table 1). However, very low recruit numbers across the region for some species precluded the spatial analysis of synchrony for the full set of 26 time series at 16 sites. The set of recruitment time series to be analyzed was thus reduced to 15: 2 species with direct development, the bivalve Lasaea sp. and the gastropod Eatoniella glomerosa; 5 with lecitotrophic larvae; and 8 with planktotrophic larvae (Table 1). Hence, our results are based on the regionally common and more abundant species found in collectors.
The barnacles Jehlius cirratus, Notochthamalus scabrosus, and Notobalanus flosculus, and the mussel Perumytilus purpuratus exhibited the highest recruitment rates (Fig. 2A-C, E), reaching maximum rates during austral spring-summer (i.e. late October to December 2002) and in localities around the center of the studied region (Fig. 1). Timing of recruitment for the mussel Semimytilus algosus (Fig. 2F) and the pulmonate limpet Siphonaria lessoni (Fig. 2I) was similar to that observed for barnacles, but different in spatial distribution. Other intertidal bivalves and gastropods showed less clear spatio-temporal patterns, with low and less localized recruitment throughout the study period. Recruitment appeared local and sporadic for species with direct development such as the bivalve Lasaea sp. (Fig. 2D) and the gastropod Eatoniella glomerosa (Fig. 2K). On the other hand, similar spatial-temporal patterns were observed for species of bivalves and gastropods, such as Brachidontes granulata (Fig. 2G), Prisogaster niger (Fig. 2M), and Mitrella unifasciata (Fig. 2J), which showed the lowest rates of recruitment.
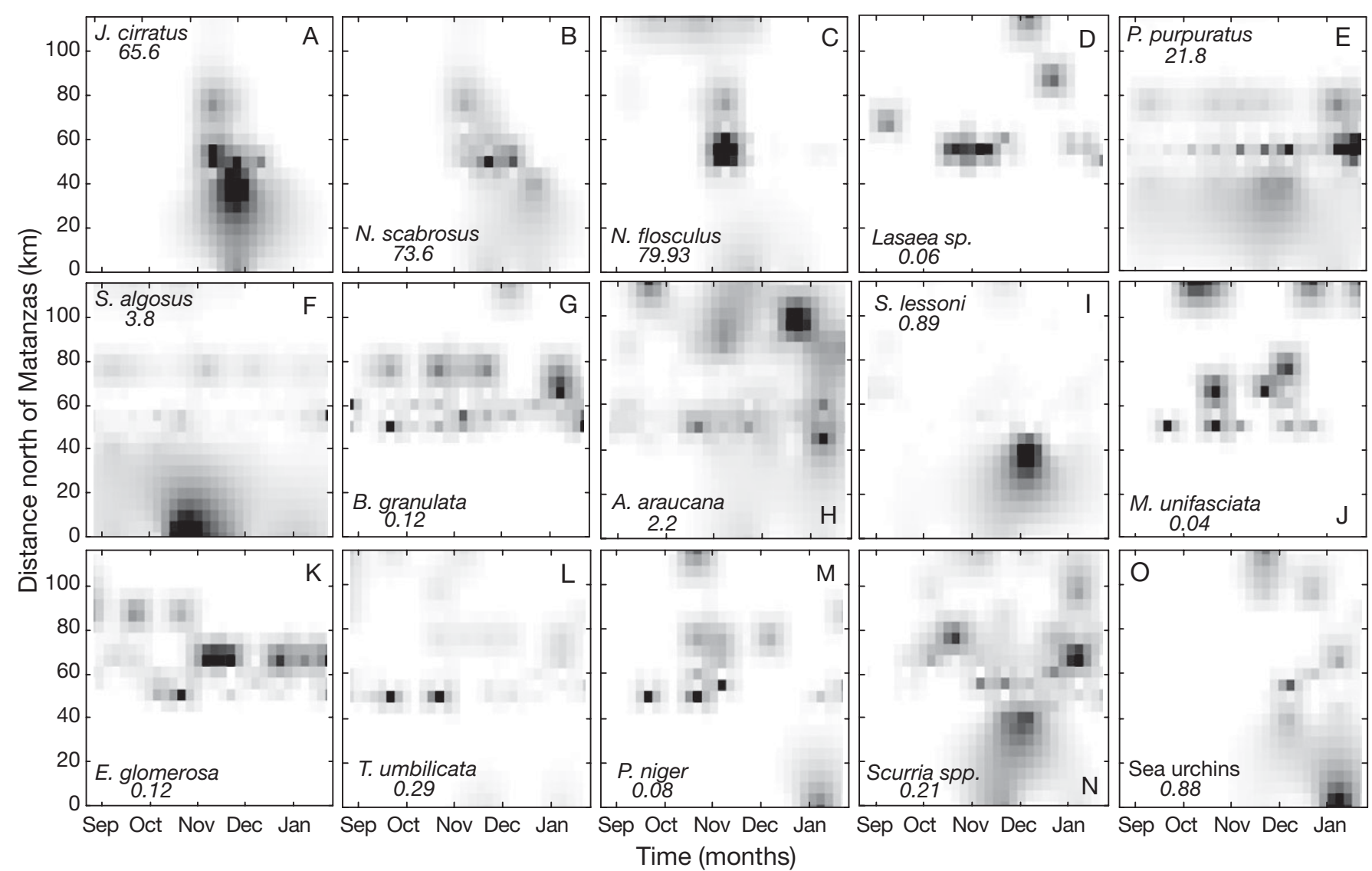

Fig. 2. Spatio-temporal patterns of variability in recruitment of $(A-C)$ barnacles, $(D-G)$ bivalves, $(H-N)$ gastropods, and $(O)$ sea urchins along the study area (see Table 1 for full species names). Data were interpolated by ordinary point kriging. With the exception of Perumytilus purpuratus, shading of each panel is scaled so that black corresponds to the maximum observed recruitment rate (ind. collector ${ }^{-1} \mathrm{~d}^{-1}$ ), indicated by the number below each species name. The scale was truncated for P. purpuratus, and black represents values $\geq 4$ ind. collector ${ }^{-1} \mathrm{~d}^{-1}$. Time period on the $x$-axis corresponds to August 2002 to January 2003 

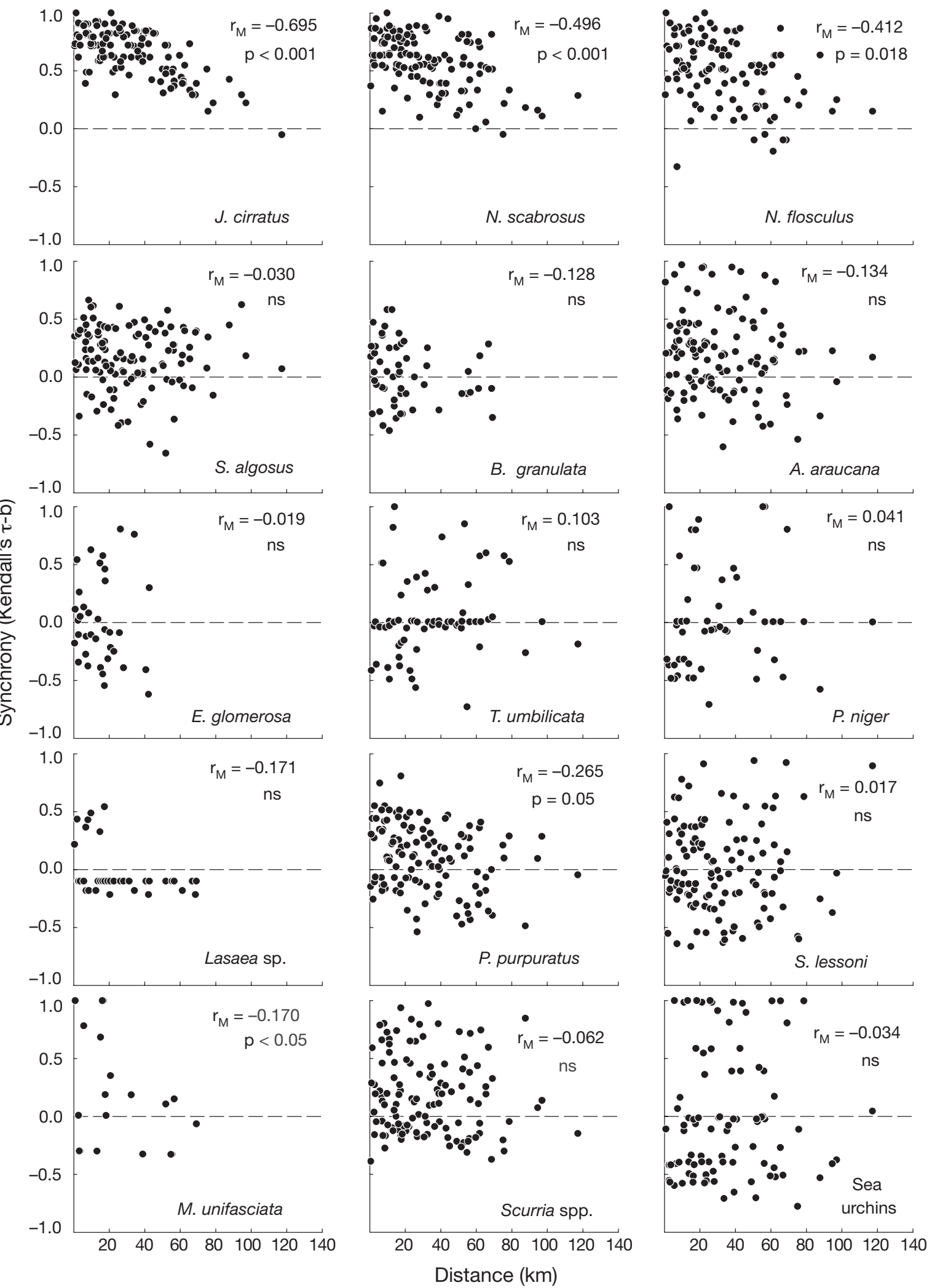

Fig. 3. Spatial synchrony in recruitment, plotted as a function of among-site distance. Each dot corresponds to a pairwise temporal correlation in recruitment $(\tau$-b) for a given species (see Table 1 for species names). Dashed line indicates temporal correlation among sites expected under the null hypothesis. Significance of $\mathrm{r}_{\mathrm{M}}$, the standardized Mantel statistic, was assessed through 1000 permutations of the distance matrix. ns: not significant 
The strength of synchrony (i.e. temporal Kendall correlation among sites) varied greatly among species, especially at scales smaller than ca. $35 \mathrm{~km}$ (Fig. 3). Recruitment of all 3 barnacles and the mussel Perumytilus purpuratus had a consistent and significant decay in synchrony with geographic distance (Fig. 3). Finally, a marginally significant pattern of decay in recruitment synchrony was found for the gastropod Mitrella unifasciata (Fig. 3, Table 1), which was found in low numbers at 7 sites and, therefore, is no longer considered here. No other species of bivalve, gastropod, or sea urchin, regardless of mode of development, showed a significant spatial synchrony pattern (Fig. 3, Table 1).

To further explore the nature of the synchrony patterns for the 4 species with high recruitment rates and significant spatial decay in synchrony, we computed Mantel correlograms. The standardized Mantel correlograms showed positive values (i.e. among-site correlation $>$ mean correlation across the study region) for sites located at distances $<30 \mathrm{~km}$ apart, and negative values for sites $>40 \mathrm{~km}$ apart (Fig. 4A). Characteristic scales of synchrony for chthamalid barnacles (Jehlius cirratus and Notochthamalus scabrosus) remained almost unchanged when Mantel correlograms were computed only with the low-frequency (months) trend in the data (Fig. 4B), and were flat and non-significant when only short-term fluctuations (biweekly) in recruitment were considered (Fig. 4C). Thus, the spatial synchrony pattern in chthamalid species appears related to processes occurring on a scale of 1 to several months. Spatial synchrony patterns in recruitment of Notobalanus flosculus were slightly different, with lack of significant positive synchrony over short distances (10 to $20 \mathrm{~km}$ ) for both raw data and the seasonal trend, and a significant spatial decay in synchrony when considering only short-term fluctuations (Fig. 4C). As for the mussel Perumytilus purpuratus, the marginally significant pattern of regional synchrony observed in Fig. 3 resulted in significant positive and negative correlations at distances of 20 and $70 \mathrm{~km}$, respectively, when the Mantel correlogram was computed for the raw dataset. Mantel correlograms were flat and non-significant when calculated for low frequency and biweekly fluctuations in P. purpuratus recruitment (Fig. 4).

Fluctuations in SST occurred synchronously along the study region, showing significant mesoscale struc-

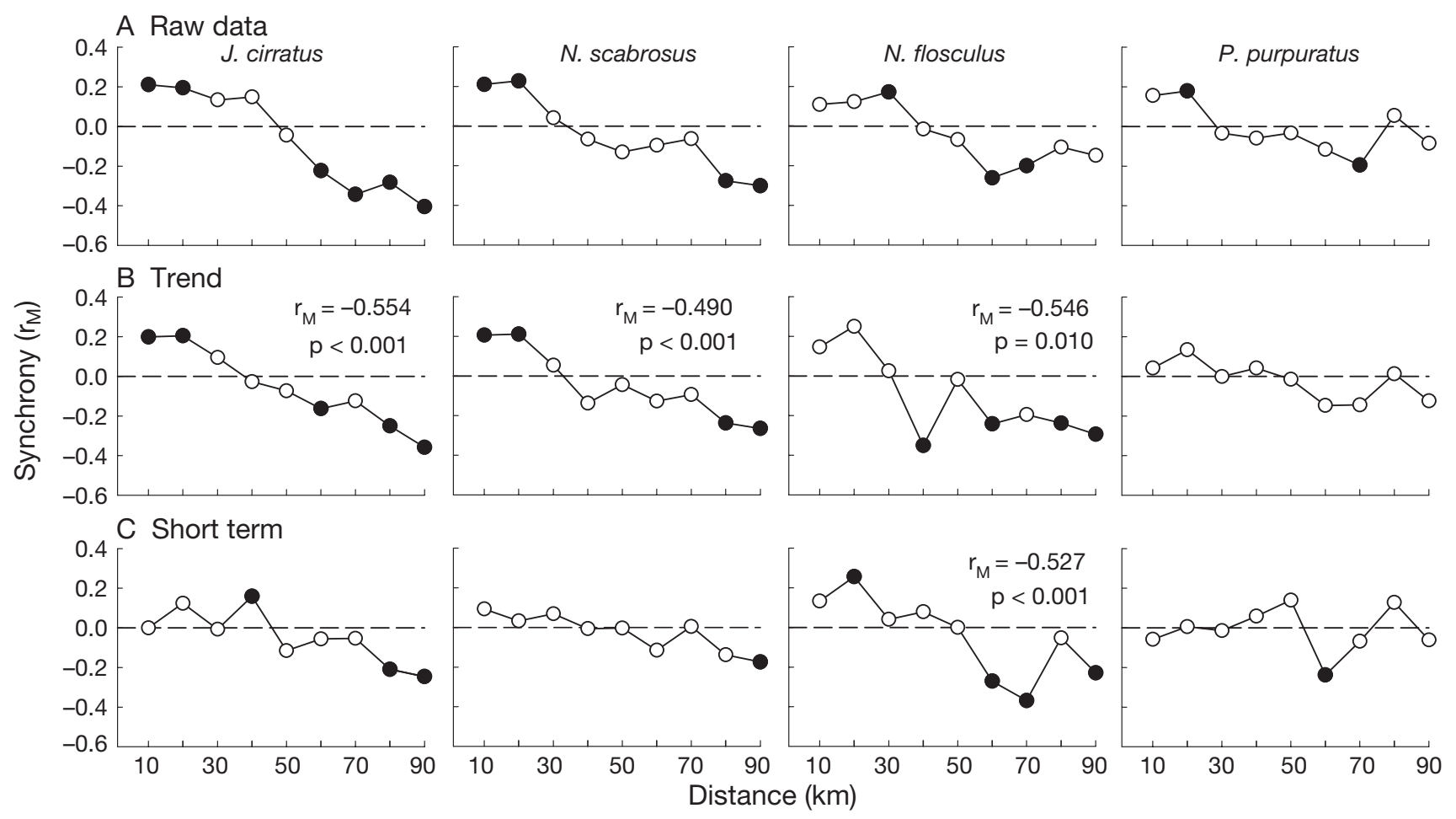

Fig. 4. Standardized Mantel correlograms computed using (A) the raw data series, (B) seasonal trend, and (C) short-term fluctuations, in recruitment of taxa with significant synchrony patterns (see Table 1 for full species names), as indicated by Mantel correlation coefficients (see Fig. 3). Positive (negative) values indicate that Mantel correlations at the corresponding distance bins are higher (lower) than the mean regional (i.e. background) among-site correlation. The seasonal trend used in B was obtained for each local recruitment series by fitting a third-order polynomial, whereas short-term fluctuations were calculated by first-differencing the raw series of recruitment rates (i.e. difference between consecutive sampling dates; see 'Materials and methods'). Significance for each distance bin was assessed through 1000 permutations. Black symbols indicate significant correlations at $\alpha=0.05$ 


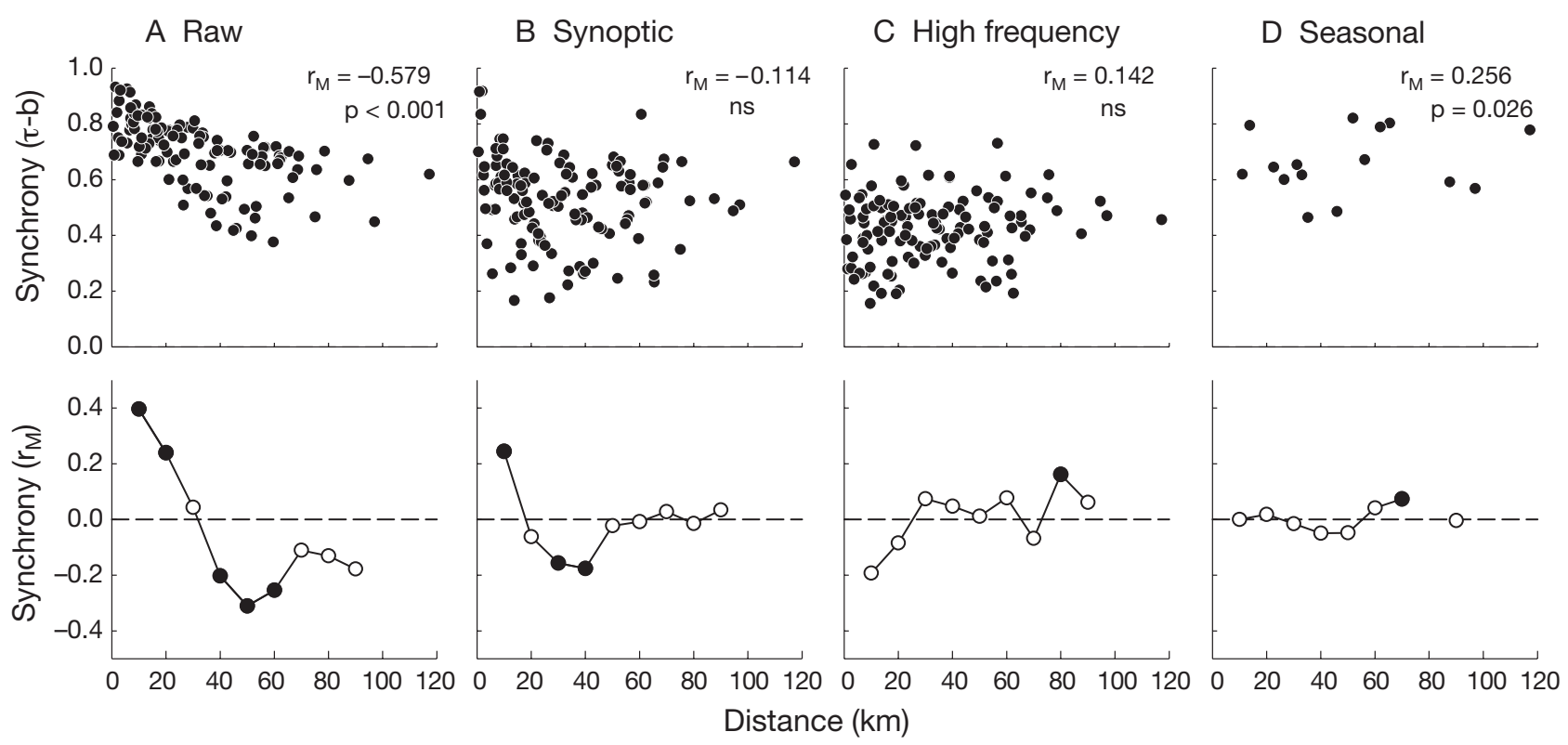

Fig. 5. Spatial synchrony of SST fluctuations recorded at each study site. Analyses were performed with the raw dataset (A) and $(B, C) 2$ filtered 7 mo time series (B: synoptic, C: high frequency; see 'Materials and methods'). A 4 yr series of monthly means (D) was analyzed to assess spatial synchrony in the seasonal cycle. Top panels: pairwise temporal correlations in SST as a function of among-site distance. Bottom panels: Mantel correlograms computed for each series, with filled black circles indicating significant correlations at $\alpha=0.05$

ture and a characteristic scale of ca. $30 \mathrm{~km}$ when the Mantel correlogram was computed for the raw SST data series (Fig. 5A). The spatial scaling of raw SST data was roughly similar to that observed for barnacle and mussel recruitment (Fig. 4). Decomposing fluctuations of SST into synoptic and high-frequency (hourly to daily) fluctuations showed that the strong spatial synchrony pattern in SST was observed at synoptic scales (Fig. 5B), but absent when higher-frequency variability was analyzed (Fig. 5C). Finally, seasonal SST variability observed over a 4 yr period was synchronous across the study region, with no evident pattern of decay as a function of distance among sites within the study region (Fig. 5D).

\section{DISCUSSION}

We found variable patterns of spatial synchrony in the recruitment of benthic invertebrates over $120 \mathrm{~km}$ of the coast of central Chile. In discussing these results, it is important to bear in mind the distinction between (1) synchronous recruitment (spatial synchrony), (2) a decay in recruitment synchrony with distance (spatial synchrony pattern) and (3) the persistence of spatial patterns in recruitment, which might be observed when integrating over longer times, such as over a recruitment season (not addressed in this study). The negative relationship between temporal correlation and distance among pairs of sites suggested by a spa- tial synchrony pattern was significant only for species with both planktonic larvae and high settlement rates along the study region. Although at the temperatures recorded during our study (see Lagos et al. 2005), duration of the planktonic larval phase for the 4 species showing synchrony could be $>1$ mo (Ramorino \& Campos 1979, Venegas et al. 2000, O'Connor et al. 2007), scales of larval dispersal were adequately resolved by the spatial and temporal resolution of our study. All 4 species showed a similar distance-dependent decay in recruitment synchrony, with a switch from positively correlated fluctuations for sites separated by $<30 \mathrm{~km}$ to negatively correlated fluctuations for sites $>40 \mathrm{~km}$ apart. Similar scales of synchrony have been reported for benthic mollusks (Burrows et al. 2002), and the visual inspection of spatial time series reported by a number of authors (e.g. Connell 1985, Ebert et al. 1994, Jenkins et al. 2000) suggests that mesoscale synchrony in the recruitment of sessile benthic invertebrates may be a common but underreported phenomenon.

The absence of detectable synchrony patterns (i.e. decay with distance) in the remaining 11 species for which we could perform analyses could be ascribed to their low abundance in the study region, or that other pre- and post-settlement processes occurring over smaller spatial-temporal scales are mostly responsible for the variability in recruitment detected at a given site. This is especially likely for species with limited potential for larval dispersal (e.g. direct development, 
lecithotrophic larvae; see Shanks et al. 2003), for which our coarse spatial resolution could have missed otherwise synchronous fluctuations occurring at smaller spatial scales. Conversely, the space covered by the study region could be too small to observe a clear decay in recruitment synchrony for some species, but in this case one would expect positive correlations across the region, which is generally not the case. Furthermore, our recruitment data series, and the very definition of recruitment in this study, were based on biweekly observations. Such a sampling interval may have been inadequate for species in which shortterm, more local processes could greatly influence recruitment patterns.

The spatial scales of recruitment synchrony detected in this study for species with planktonic larvae highlight the great potential for larval dispersal to synchronize the dynamics of marine populations tens of $\mathrm{km}$ apart. Unlike terrestrial animals such as moths, aphids, or grouse (Hanski \& Woiwod 1993, Lindström et al. 1996), dispersal can play a major role in synchronizing the dynamics of distant marine populations, especially in species where adults are sessile and where the renewal of local populations depends greatly on the external supply and settlement of dispersive larval stages (Roughgarden et al. 1988). At some temporal scales, and given critical assumptions regarding nearshore hydrodynamics and larval cohesiveness in the plankton, synchronous recruitment of benthic invertebrates could arise in the absence of dispersal, purely from the synchronous production of larvae across the study region (Pineda 2000). It could also result from dispersal alone, in which case the spatial pattern of synchrony is expected to show a decorrelation scale that is proportional to a species' dispersal potential. Recent observations across the $120 \mathrm{~km}$ study area (M. Fernández unpubl. data) suggest that reproduction of benthic invertebrates in this region is more or less synchronous, with no clear spatial trends. This is not surprising, considering that over the $120 \mathrm{~km}$ encompassed by our sites there is no apparent latitudinal trend in SST variability (Narváez et al. 2004, 2006). In fact, the analysis of 4 yr series of monthly means for SST at 6 of the 16 sites in this study showed that temperature fluctuates synchronously across the study area, with no apparent decline in synchrony as amongsite distance increases. Hence, considering that sea water temperature is a key factor for reproductive timing and larval duration in benthic invertebrates (O'Connor et al. 2007), we regard the observed pattern of recruitment synchrony as a manifestation of dispersal and expect it to vary according to inter-specific differences in larval duration (i.e. dispersal capabilities). This argument provides the basis to test competing hypotheses about underlying processes that may syn- chronize population dynamics and community structure over larger spatial scales.

Our results are consistent with the scales of spatial synchrony expected for open populations in which benthic-oceanic coupling is forced by mesoscale physical processes through larval dispersal, aggregation at offshore fronts, and delivery to shore (Roughgarden et al. 1988, Connolly \& Roughgarden 1998, Aiken et al. 2007). Botsford (2001) showed that spatial variability in physical conditions along the California upwelling system drives spatial variation in recruitment patterns of crabs and sea urchins over $100 \mathrm{~km}$ scales and suggested that mechanisms associated with upwelling relaxation may set the spatial scale for recruitment of these taxa. We observed a distance-dependent decay in synchrony of in situ SST variability that at distances $<30 \mathrm{~km}$ resembled the pattern found for recruitment in species with planktotrophic larvae. Recent observations of nearshore plankton distributions within the study area (Vargas et al. 2006) indicate that larvae of these species tend to occur near the surface, and a 3dimensional circulation model of the same region (Aiken et al. 2007) demonstrated that coastal flows respond mostly to wind forcing on the surface ocean, and that interaction with coastal topography can create complex, non-Euclidian patterns of connectivity along the coast. This information and the fact that high-frequency (hourly) SST fluctuations do not show a characteristic scale of variability - or that such a scale is smaller than the resolution provided by our observations - suggest that mesoscale circulation and crossshore transport induced by coastal upwelling may indeed have a disproportionate effect on the timing and spatial structure of larval arrival to intertidal environments. In light of recent estimates for dispersal kernels in the region (Aiken et al. 2007) and the results presented in this contribution, we hypothesize that mesoscale coastal upwelling sets the characteristic scale of spatial synchrony in recruitment, whereas the shape of the synchrony pattern is determined by the dispersal capabilities of larvae. Topographically modulated flows have the potential to decouple recruitment at nearby sites (Aiken et al. 2007) and could therefore explain the existence of weak or even negative correlations between recruitment time series of sites in geographic proximity (Fig. 3). Given our results, it is tempting to infer that recruitment of planktotrophic species that did not show significant spatial synchrony is not affected by upwelling processes in the same manner, but further studies are needed to determine the mechanisms and the scales of variability behind these patterns.

Populations of sessile benthic invertebrates are usually regarded as consisting of disjunct local populations linked by oceanographically mediated larval 
dispersal, meaning that at some scale, populations are neither isolated nor completely connected (Botsford et al. 1998). In this context, our findings and those of previous studies in central Chile (e.g. Lagos et al. 2005, Navarrete et al. 2005) contribute valuable information to the development of management and conservation strategies that are spatially explicit, such as the design of marine reserve networks. The spatial scaling of recruitment identified here for 3 barnacles and 1 mussel provides clues as to the relevant scales for population regulation and the spacing of marine reserves (Shanks et al. 2003). However, our data also show large variability in synchrony patterns among species, which casts doubt on management recommendations based on mono-specific biological or numerical models. One could argue that since the 4 species that showed clear patterns of spatial synchrony are the numerically or ecologically dominant species in this system (Navarrete \& Castilla 2003, Navarrete et al. 2005), they could drive the spatial dynamics of the entire intertidal meta-community by affecting the spatial dynamics of species with which they interact (Holyoak et al. 2005). At present, however, there is no information to substantiate meta-community types of effects. Further studies are necessary to understand how spatio-temporal coherence in recruitment corresponds to adult abundance and community structure. Such knowledge will foster significant advances in understanding population regulation and community dynamics of marine organisms.

Acknowledgements. O. Lúa, D. Narváez, A. Piñones, M. Pacheco, and E. Wieters helped us during this field-intensive study. N.A.L. and F.J.T. acknowledge post-doctoral support by the Andrew Mellon Foundation through a grant to S.A.N. and J.C.C. N.A.L. also acknowledges project INV-1-04-07 (UST). This study was funded by a FONDAP-FONDECYT grant (15001-0001) to the Center for Advanced Studies in Ecology and Biodiversity. Additional funds were provided by FONDECYT \#1040787 to S.A.N.

\section{LITERATURE CITED}

Aiken CM, Navarrete SA, Castillo MI, Castilla JC (2007) Along-shore larval dispersal kernels in a numerical ocean model of the central Chilean coast. Mar Ecol Prog Ser 339: 13-24

Bjørnstad ON, Bolker B (2000) Canonical functions for dispersal-induced synchrony. Proc R Soc Lond B 267:1787-1794

Bjørnstad ON, Ims RA, Lambin X (1999) Spatial population dynamics: analyzing patterns and processes of population synchrony. Trends Ecol Evol 14:427-432

Botsford LW (2001) Physical influences on recruitment to California Current invertebrate populations on multiple scales. ICES J Mar Sci 58:1081-1091

Botsford LW, Moloney CL, Largier JL, Hastings A (1998) Metapopulation dynamics of meroplanktonic invertebrates: the Dungeness crab (Cancer magister) as an example. Can Spec Publ Fish Aquat Sci 125:296-306
Buonaccorsi JP, Elkinton JS, Evans SR, Liebhold AM (2001) Measuring and testing for spatial synchrony. Ecology 82: 1668-1679

Burrows M, Moore J, James B (2002) Spatial synchrony of population changes in rocky shore communities in Shetland. Mar Ecol Prog Ser 240:39-48

Connell JH (1985) The consequences of variation in initial settlement vs. post-settlement mortality in rocky intertidal communities. J Exp Mar Biol Ecol 93:11-45

Connolly SR, Roughgarden J (1998) A latitudinal gradient in northeast Pacific intertidal community structure: evidence for an oceanographically based synthesis of marine community theory. Am Nat 151:311-326

Connolly SR, Roughgarden J (1999) Increased recruitment of northeast Pacific barnacles during the 1997 El Niño. Limnol Oceanogr 44:466-469

Connolly SR, Menge BA, Roughgarden J (2001) A latitudinal gradient in recruitment of intertidal invertebrates in the northeast Pacific Ocean. Ecology 82:1799-1813

Ebert TA, Schroeter SC, Dixon JD, Kalvass P (1994) Settlement patterns of red and purple sea urchins (Strongylocentrotus franciscanus and $S$. purpuratus) in California, USA. Mar Ecol Prog Ser 111:41-52

Eckert G (2003) Effects of the planktonic period on marine population fluctuations. Ecology 84:372-383

Fortin MJ, Boots B, Csillag F, Remmel TK (2003) On the role of spatial stochastic models in understanding landscape indices in ecology. Oikos 102:203-212

Hanski I, Woiwod I (1993) Spatial synchrony in the dynamics of moth and aphid populations. J Anim Ecol 62:656-668

Holyoak M, Leibold MA, Mouquet N, Holt RD, Hoopes MF (2005) Metacommunities: A framework for large-scale community ecology. In: Holyoak M, Leibold MA, Holt RD (eds) Metacommunities: spatial dynamics and ecological communities. University Of Chicago Press, Chicago, IL, p 1-31

Jenkins SR, Åberg P, Cervin G, Coleman RA and 9 others (2000) Spatial and temporal variation in settlement and recruitment of the intertidal barnacle Semibalanus balanoides (L.) (Crustacea: Cirripedia) over a European scale. J Exp Mar Biol Ecol 243:209-225

Kinlan BP, Gaines SD (2003) Propagule dispersal in marine and terrestrial environments: a community perspective. Ecology 84:2007-2020

Labra FA, Lagos NA, Marquet PA (2003) Dispersal and transient dynamics in metapopulations. Ecol Lett 6:197-204

Lagos NA, Navarrete SA, Veliz F, Masuero A, Castilla JC (2005) Meso-scale spatial variation in settlement and recruitment of intertidal barnacles along the coast of central Chile. Mar Ecol Prog Ser 290:165-178

Legendre P, Legendre L (1998) Numerical ecology, 2nd edn. Elsevier Science, Amsterdam

Levin LA, Bridges TS (1995) Pattern and diversity in reproduction and development. In: McEdward L (ed) Ecology of marine invertebrate larvae. CRC Press, Boca Raton, FL, p 1-48

Liebhold A, Koenig WD, Bjornstad ON (2004) Spatial synchrony in population dynamics. Annu Rev Ecol Evol Syst 35:467-490

Lindström J, Ranta E, Lindén H (1996) Large-scale synchrony in the dynamics of capercaillie, black grouse and hazel grouse populations in Finland. Oikos 76:221-227

Mantel (1967) The detection of disease clustering and a generalized regression approach. Cancer Res 27:209-220

Martínez P, Navarrete SA (2002) Temporal and spatial variation in settlement of the gastropod Concholepas concholepas in natural and artificial substrata. J Mar Biol Assoc UK 82:257-264 
Menge BA (2000) Recruitment vs. postrecruitment processes as determinants of barnacle population abundance. Ecol Monogr 70:265-288

Narváez D, Poulin E, Leiva G, Hernandez E, Castilla JC, Navarrete SA (2004) Seasonal and spatial variation of nearshore hydrographic conditions in central Chile. Cont Shelf Res 24:279-292

Narváez DA, Navarrete SA, Largier J, Vargas CA (2006) Onshore advection of warm water, larval invertebrate settlement, and relaxation of upwelling off central Chile. Mar Ecol Prog Ser 309:159-173

Navarrete SA, Castilla JC (2003) Experimental determination of predation intensity in an intertidal predator guild: dominant versus subordinate prey. Oikos 100:251-262

Navarrete SA, Broitman B, Wieters EA, Finke GR, Venegas RM (2002) Recruitment of intertidal invertebrates in the southeast Pacific: interannual variability and the 1997-1998 El Niño. Limnol Oceanogr 47:791-802

Navarrete SA, Wieters EA, Broitman BR, Castilla JC (2005) Scales of benthic-pelagic coupling and the intensity of species interactions: from recruitment limitation to topdown control. Proc Natl Acad Sci USA 102:18046-18051

O'Connor MI, Bruno JF, Gaines SD, Halpern BS, Lester SE, Kinlan BP, Weiss JM (2007) Temperature control of larval dispersal and the implications for marine ecology, evolution, and conservation. Proc Natl Acad Sci USA 104: 1266-1271

Pineda J (2000) Linking larval settlement to larval transport: assumptions, potentials, and pitfalls. In: Färber-Lorda J (ed) Oceanography of the Eastern Pacific, Vol 1. CICESE, Ensenada, p 84-105

Editorial responsibility: Otto Kinne (Editor-in-Chief), Oldendorf/Luhe, Germany
Ramorino L, Campos B (1979) Desarrollo larval y post-larval de Perumytilus purpuratus (Lamarck, 1819) Bivalvia: Mytilidae. Ann Mus Hist Nat Valparaíso 12:207-218

Ranta E, Kaitala V, Lindstrom J, Helle E (1997) The Moran effect and synchrony in population dynamics. Oikos 78: 136-142

Roughgarden J, Gaines SD, Possingham H (1988) Recruitment dynamics in complex life cycles. Science 241:1460-1466

Shanks AL, Grantham BA, Carr MH (2003) Propagule dispersal distance and the size and spacing of marine reserves. Ecol Appl 13:S159-S169

Siegel DA, Kinlan BP, Gaylord B, Gaines SD (2003) Lagrangian descriptions of marine larval dispersion. Mar Ecol Prog Ser 260:83-96

Strathmann MF (1987) Reproduction and development of marine invertebrates of the Northern Pacific coast. University of Washington Press, Seattle, WA

Thorson G (1950) Reproductive and larval ecology of marine bottom invertebrates. Biol Rev 25:1-45

Vargas CA, Narváez DA, Piñones A, Navarrete SA, Lagos NA (2006) River plume dynamics influence transport of barnacle larvae in the inner shelf off central Chile. J Mar Biol Assoc UK 86:1057-1065

Venegas RM, Ortiz V, Olguin A, Navarrete SA (2000) Larval development of the intertidal barnacles Jehlius cirratus and Notochthamalus scabrosus (Cirripedia: Chthamalidae) under laboratory conditions. J Crustac Biol 20: 495-504

Wieters E (2005) Upwelling control of positive interactions over mesoscales: a new link between bottom-up and top-down processes on rocky shores. Mar Ecol Prog Ser 301:43-54

Submitted: March 27, 2007; Accepted: June 14, 2007

Proofs received from author(s): October 19, 2007 